\title{
Cushion plant Silene acaulis is a pioneer species at abandoned coal piles in the High Arctic, Svalbard
}

\author{
Minwoo Oh and Eun Ju Lee
}

\begin{abstract}
Background: Abandoned coal piles after the closure of mines have a potential negative influence on the environment, such as soil acidification and heavy metal contamination. Therefore, revegetation by efficient species is required. For this, we wanted to identify the role of Silene acaulis in the succession of coal piles as a pioneer and a nurse plant. S. acaulis is a well-studied cushion plant living in the Arctic and alpine environments in the northern hemisphere. It has a highly compact cushion-like form and hosts more plant species under its canopy by ameliorating stressful microhabitats. In this research, we surveyed vegetation cover on open plots and co-occurring species within S. acaulis cushions in coal piles with different slope aspects and a control site where no coal was found. The plant cover and the similarity of communities among sites were compared. Also, the interaction effects of $S$. acaulis were assessed by rarefaction curves.

Results: S. acaulis was a dominant species with the highest cover (6.7\%) on the coal piles and occurred with other well-known pioneer species. Plant communities on the coal piles were significantly different from the control site. We found that the pioneer species S. acaulis showed facilitation, neutral, and competition effect in the north-east facing slope, the south-east facing slope, and the flat ground, respectively. This result was consistent with the stress gradient hypothesis because the facilitation only occurred on the north-east facing slope, which was the most stressed condition, although all the interactions observed were not statistically significant.

Conclusions: $S$. acaulis was a dominant pioneer plant in the succession of coal piles. The interaction effect of $S$. acaulis on other species depended on the slope and its direction on the coal piles. Overall, it plays an important role in the succession of coal piles in the High Arctic, Svalbard.
\end{abstract}

Keywords: Pioneer species, Facilitation, Silene acaulis, Coal pile, Cushion plant, High arctic, Svalbard

\section{Introduction}

Coal mining has been dramatically reduced worldwide, and many coal piles have been abandoned after the closure of mines. If it is not appropriately reclaimed, dissolved pollutants are carried in runoffs and flows into streams (Carter and Ungar 2002), and soils are acidified and contaminated by heavy metals (Hollesen et al. 2009). For these reasons, there were many attempts to restore the abandoned coal piles by replanting trees or

* Correspondence: ejlee@snu.ac.kr

School of Biological Sciences, Seoul National University, Seoul 08826, Republic of Korea spreading seeds (Singh and Singh 2006; Moreno-de las Heras et al. 2008; Dowarah et al. 2009; Alday et al. 2012; Fields-Johnson et al. 2012).

There are many abandoned coal piles in Svalbard, and it polluted surrounding areas with their acid mine drainage (AMD) (Søndergaard et al. 2007). Oxidation of pyrite $\left(\mathrm{FeS}_{2}\right)$ from rock fragments on a coal pile produces sulfuric acid, and this leads to heavy metal dissociation. As a result, AMD contains accumulated heavy metals, such as $\mathrm{Fe}, \mathrm{Al}, \mathrm{Mn}, \mathrm{Zn}$, and $\mathrm{Ni}$ (Søndergaard et al. 2007). Among them, $\mathrm{Al}$ and $\mathrm{Mn}$ exist as dissolved forms and often cause plant damage (Elberling et al. 2007).

(c) The Author(s). 2021 Open Access This article is licensed under a Creative Commons Attribution 4.0 International License, which permits use, sharing, adaptation, distribution and reproduction in any medium or format, as long as you give appropriate credit to the original author(s) and the source, provide a link to the Creative Commons licence, and indicate if changes were made. The images or other third party material in this article are included in the article's Creative Commons licence, unless indicated otherwise in a credit line to the material. If material is not included in the article's Creative Commons licence and your intended use is not permitted by statutory regulation or exceeds the permitted use, you will need to obtain permission directly from the copyright holder. To view a copy of this licence, visit http://creativecommons.org/licenses/by/4.0/. 
Despite the cold weather in Svalbard, the core of coal piles is kept warm $\left(\sim 5{ }^{\circ} \mathrm{C}\right)$ throughout the year because of the heat generated by the microbial-driven pyrite oxidation (Elberling et al. 2007; Hollesen et al. 2009). It keeps the chemical process happening and generating AMD (Elberling et al. 2007).

Insufficient moisture and nutrient as well as poisonous AMD limit vegetation in coal waste areas in alpine tundra (Baig 1992). Such areas are efficiently colonized by some species characterized by low growth-form, low requirement of nutrients, and efficient vegetative reproduction showed better colonization ability. In the High Arctic tundra, the cushion plants, Silene acaulis, Saxifraga oppositifolia, and Saxifraga cespitosa, were observed with high coverage in an abandoned coal pile (Kojima 2004). They are characterized by low domeshaped growth-form (Aubert et al. 2014).

A cushion plant is an ecological engineer that enhances the probability of seedling recruitment and establishment by offering benign microhabitats under their canopies, such as favorable temperature, humidity, and nutrients (Frenot et al. 1998; Schöb et al. 2012; Anthelme et al. 2012; Cavieres et al. 2014). This positive interaction of cushion plants on sub-canopy plants is called the facilitation effect, and this kind of cushion plant is also called a nurse plant. Facilitation is usually found in a harsh environment, such as the Arctic, alpine tundra, or desert (Bertness and Callaway 1994; Ren et al. 2008; Dvorský et al. 2013).

S. acaulis is a perennial and long-lived densely packed hemispherical cushion plant with $2-8 \mathrm{~cm}$ height and taproot. It is commonly found in Svalbard and thrives on slightly dry gravel. This plant is widely distributed in circumpolar regions except in Siberia (Lee et al. 2014; Hermansen 2007). It is a well-studied nurse plant in the northern hemisphere, especially in the alpine environment (Antonsson et al. 2009; Molenda et al. 2012; Bonanomi et al. 2016), but its facilitation effect as a pioneer species has not been extensively studied in the High Arctic region despite its dominance in some Arctic tundra such as Svalbard (but see Kjær et al. 2018). Also, its potential for accelerating successional changes on a coal pile was not studied so far.

In this study, we focused on identifying the role of $S$. acaulis on abandoned coal piles as a pioneer and a nurse plant in the early stage of succession. S. acaulis is already known as a pioneer species in a glacier foreland that can recruit other species by facilitation (Kjær et al. 2018). However, it has not been reported that $S$. acaulis is also a pioneer species on a coal pile. Also, there are only a few studies that described the successional change of coal piles in alpine or arctic tundra (Baig 1992; Kojima 2004). We hypothesized that the floristic composition of a coal pile is different from the surrounding area where coal is not found, but $S$. acaulis is still a dominant pioneer species on a coal pile based on our observation. Also, we measured the facilitation effect of $S$. acaulis to determine its additional role in the succession of the coal pile. The facilitation effect generally accelerates ecological succession by supplying favorable microhabitats to other plants; therefore, a nurse plant can be a promising candidate to restore a disturbed area in a harsh environment (Ren et al. 2008). For this reason, we expected that $S$. acaulis also have a facilitation effect on a coal pile, and it can accelerate natural restoration of the abandoned coal piles in the High Arctic tundra.

\section{Materials and methods}

\section{Study area}

We surveyed $S$. acaulis on the abandoned coal piles on the south-east of $\mathrm{Ny}$-Ålesund, Svalbard, which is located in a northward direction from the Norwegian mainland (Fig. 1). In the study site, abandoned coal piles were scattered on the ground, and there was some vegetation, including S. acaulis (Fig. 2 a). On the coal piles, soils are not formed yet, and vegetation was sparse compared to the surrounding non-coal pile areas, which indicates its early successional stage. Coal mining was commenced in 1916 at Kongsfjorden in the north of $\mathrm{Ny}$-Ålesund and closed after the big explosion in 1962 (Hermansen 2007).

We selected three sites of coal piles for the study, which are (1) a north-east facing slope (NE), (2) a southeast facing slope (SE), and (3) a flat ground on coal piles (Fig. 1). Also, we surveyed a control site near the coal piles, in which no coal is found. Those three coal piles sites indirectly reflect the different stress conditions because the slope aspects determine the amount of incident light during the day, and the slope steepness alters the shear stress on the residing plants.

Svalbard is classified as tundra, according to the Köppen classification (Rubel and Kottek 2010). The annual mean temperature is $-4.9{ }^{\circ} \mathrm{C}$. The warmest month is July with $5.4{ }^{\circ} \mathrm{C}$ on average, and February is the coldest month with $-12.4{ }^{\circ} \mathrm{C}$ on average. Precipitation is reduced in summer and reaches the lowest point in June $(15.1 \mathrm{~mm})$, and it increases again in winter (around 40 $\mathrm{mm})$. Due to the low precipitation, Svalbard is as dry as many deserts, and the primary source of water is permafrost (Stange 2007). The harsh wind is another factor of growth inhibition. The average wind speed is $3.7 \mathrm{~m} / \mathrm{s}$. It is cold and windy but relatively favorable compared with such a far north area because of a branch of the Gulf stream flowing along the west side of Spitsbergen (Rønning 1996). All the descriptive statistics of weather information was calculated from the meteorological data from 1975 to 2017 recorded in Ny-Ålesund observation 


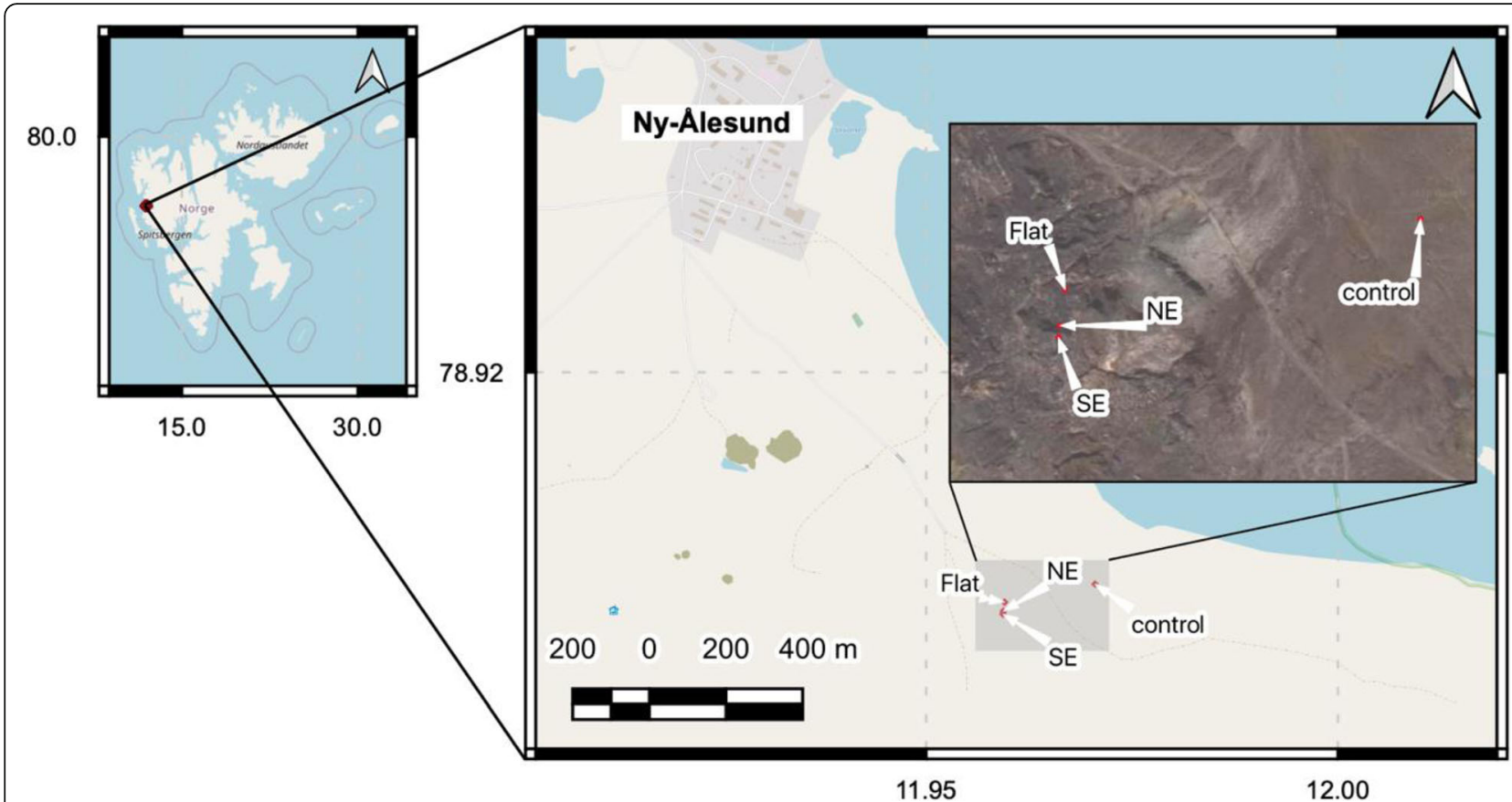

Fig. 1 The locations of the sampling sites in Ny-Ålesund, Svalbard: the control site, flat ground (Flat), north-east facing slope (NE), and the southeast facing slope (SE) on coal piles. The base map is from OpenStreetMap, Google, and Maxar Technologies

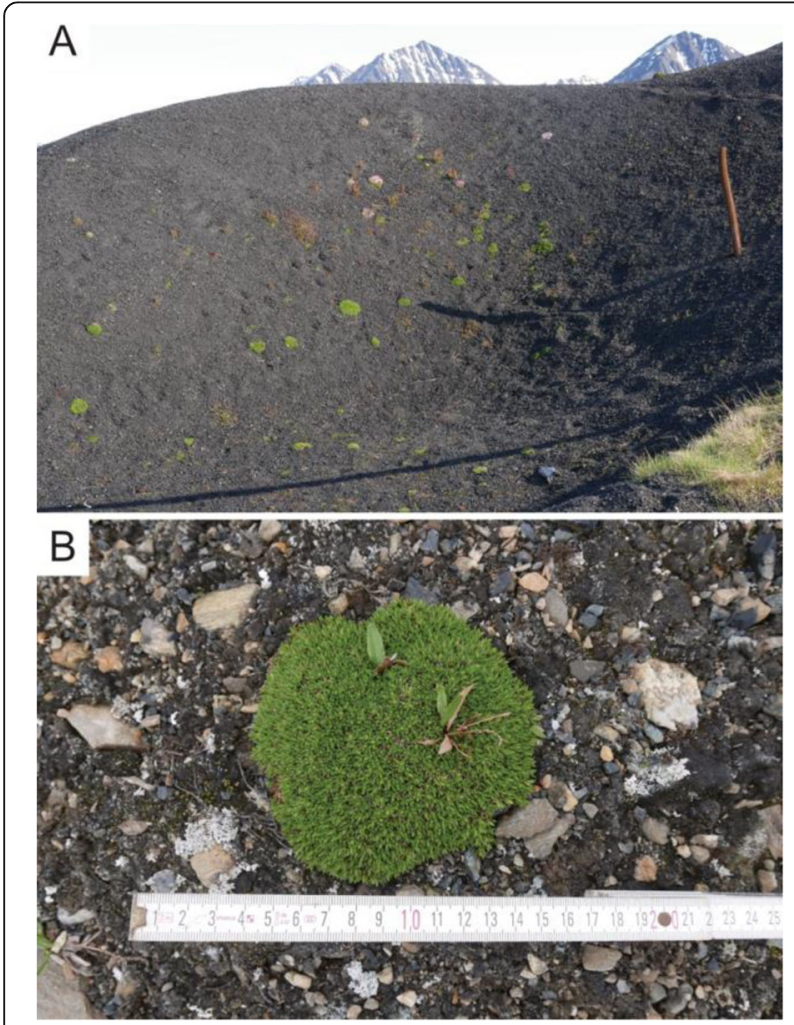

Fig. 2 S. acaulis was growing as a dominant species on the coal pile slope in Ny-Ålesund a. As a nurse plant, S. acaulis can harbor other species within its cushion. For example, Bistorta vivipara has grown out of $S$. acaulis in the photo below $\mathbf{b}$ station located at 78.9243, 11.9312 (decimal degrees), 8 m.a.s.l., about $1 \mathrm{~km}$ away from survey sites, which was acquired from eKlima, web-based climate database of The Norwegian Meteorological Institute.

\section{Sampling method}

From July 13 to 15 in 2015, we surveyed 20 of $50 \mathrm{~cm} \times$ $50 \mathrm{~cm}$ plots in an open area on the control site, NE, SE, and the flat ground on the coal piles, and we recorded vegetation coverage (\%) of all plant species found within the plots. We also haphazardly selected $300 \mathrm{~S}$. acaulis in the control site and $50 \mathrm{~S}$. acaulis in each coal pile site, and we measured their diameters and recorded the occurrence of other species within each cushion. All species were identified, according to Lee et al. (2014).

\section{Data analysis}

Plant communities among sites were compared by NMDS with Bray-Curtis dissimilarity applied to the vegetation cover recorded in $50 \mathrm{~cm} \times 50 \mathrm{~cm}$ plots. PERMANOVA tested the statistical significance of differences in plant community among three sites with 9999 permutations (Anderson 2001) followed by pairwise comparisons with Bonferroni correction. Indicator species for each site or its combinations were found if it is present using indicator value index (IndVal) with 999 permutations (Dufrêne and Legendre 1997; De Cáceres, et al. 2010). 
The sign and the magnitude of the interaction effect of $S$. acaulis on co-occurring species were indirectly analyzed by comparing two rarefaction curves of $S$. acaulis cushions and 20 of $50 \mathrm{~cm} \times 50 \mathrm{~cm}$ plots in each site. Firstly, the presence or absence of found species within each cushion was coded into 1 (presence) or 0 (absence), and a cushion-by-species incidence matrix was generated. The cushion areas were estimated by the formula of the circle area, $\pi r^{2}$, using measured diameters by assuming them to be circles. According to the randomization technique, sample order was randomized 1000 times, and cumulative area and cumulative richness were calculated (Colwell and Coddington 1994; Gotelli and Colwell 2001). However, the cumulative area was not regularly increased because the cushion area is different from each other; therefore, the usual permutation method cannot be applied to this data. The range of cumulative area was divided into 30-quantiles (30 segments). Then, the mean of the cumulative species richness and the cumulative area in each segment were calculated. Whether the segmentation number affects the result was checked, and we confirmed that the shape of curves was robust to the segmentation number unless it was too large.

The confidence interval (CI) for the rarefaction curve was calculated by parametric bootstrap. For this, the incidence probability for each species given cushion area was modeled by logistic regression. Then, a cushion by species matrix was simulated 1000 times based on the incidence probability. The rarefaction curve of each simulated matrix was computed using the same method previously described. The standard deviation of all simulated richness given the same quantile of the cumulative area was calculated. The means of cumulative areas per quantile were slightly different among simulations, but these variations were negligible. Forsythe-MalcolmMoler Spline interpolation (Forsythe et al. 1977) was applied to plot a smoother rarefaction curve.

The difference between two rarefaction curves at the same cumulative area is the absolute effect of the interaction. It cannot be compared to that of other sites without normalization unless both sites have the same species richness on open ground. Therefore, we used relative interaction intensity (RII) to normalize the magnitude of the interaction (Armas et al. 2004):

$$
\mathrm{RII}=\frac{B_{w}-B_{o}}{B_{w}+B_{o}}
$$

where $B_{w}$ is the number of species within a cushion, and it represents the community response to the interaction effect of the cushion. $B_{o}$ is the number of species in an open area, and it represents the basal species richness without interaction effect. RII is symmetrical and ranging from - 1 to 1 . The negative RII is interpreted as competition, and the positive RII is interpreted as facilitation. This index has been widely used to study the interaction effect of plants in ecology literature (Schöb et al. 2013; Bonanomi et al. 2016; Kjær et al. 2018; Liu et al. 2020).

$B_{w}$ and $B_{o}$ can be obtained in the rarefaction curves, but the cumulative area should be rarefied to the same level. This is because as the sampling effort increases, so does the species richness. It means that the species richness at the minimum cumulative area of all sites should be calculated and compared. The minimum cumulative area among three sites on coal piles was $6658 \mathrm{~cm}^{2}$, which was observed in the NE. Given this area, species richness per site was calculated by Forsythe-MalcolmMoler spline interpolation (Forsythe et al. 1977) of the rarefaction curve. The variance of RII was calculated by a general formula of propagation of error with the interpolated richness and standard deviation of richness.

Since the cushion size can be another factor to determine interaction, its logarithmic transformation was compared among three sites by a one-way ANOVA test followed by Tukey's HSD for post hoc analysis. Before the tests, the 300 cushion samples were reduced to 50 by undersampling without replacement to resolve the imbalanced data problem. Also, the relationship between the median cushion size and the RII was visually assessed.

All the analyses were performed in $\mathrm{R}$ 4.0.2 ( $\mathrm{R}$ Core Team 2020) with the package vegan version 2.5.6 for NMDS and PERMANOVA (Oksanen et al. 2019) and the package indicspecies version 1.7 .9 for indicator species analysis (De Cáceres and Legendre 2009).

\section{Results}

Plant communities on the coal piles and the control site $S$. acaulis had the highest cover on the open plots of coal piles, followed by S. oppositifolia, Luzula confusa, and others (S. acaulis $6.7 \pm 5.9 \%$, S. oppositifolia $3.5 \pm$ $3.0 \%$, L. confusa $3.0 \pm 4.6 \%$, Bistorta vivipara $1.8 \pm 2.2 \%$, Oxyria digyna $1.2 \pm 2.9 \%$, Salix polaris $0.7 \pm 1.5 \%$, Poa alpina $0.3 \pm 1.6 \%$, Equisetum scirpoides $0.2 \pm 1.4 \%, S$. cespitosa $0.1 \pm 0.3 \%$, the others: below $0.1 \%$, all values are mean \pm s.d.) (Fig. 3). However, on the control site, $L$. confusa had the highest cover, followed by $S$. polaris, $S$. acaulis, B. vivipara, and others (S. acaulis $9.9 \pm 7.1 \%, S$. oppositifolia $2.7 \pm 2.3 \%$, L. confusa $13.3 \pm 6.2 \%$, B. vivipara $9.8 \pm 9.0 \%$, O. digyna $0.3 \pm 0.7 \%$, S. polaris $12.0 \pm$ $5.2 \%$, S. cespitosa $0.1 \pm 0.5 \%$, Draba alpina $0.2 \pm 0.4 \%$, Micranthes hieracifolia $0.1 \pm 0.3 \%$, Minuartia biflora 1.4 $\pm 1.2 \%$, all values are mean \pm s.d.).

We found that the plant community of control site was significantly different from that of the coal piles (Fig. 4). Among three sites on the coal piles, the flat 


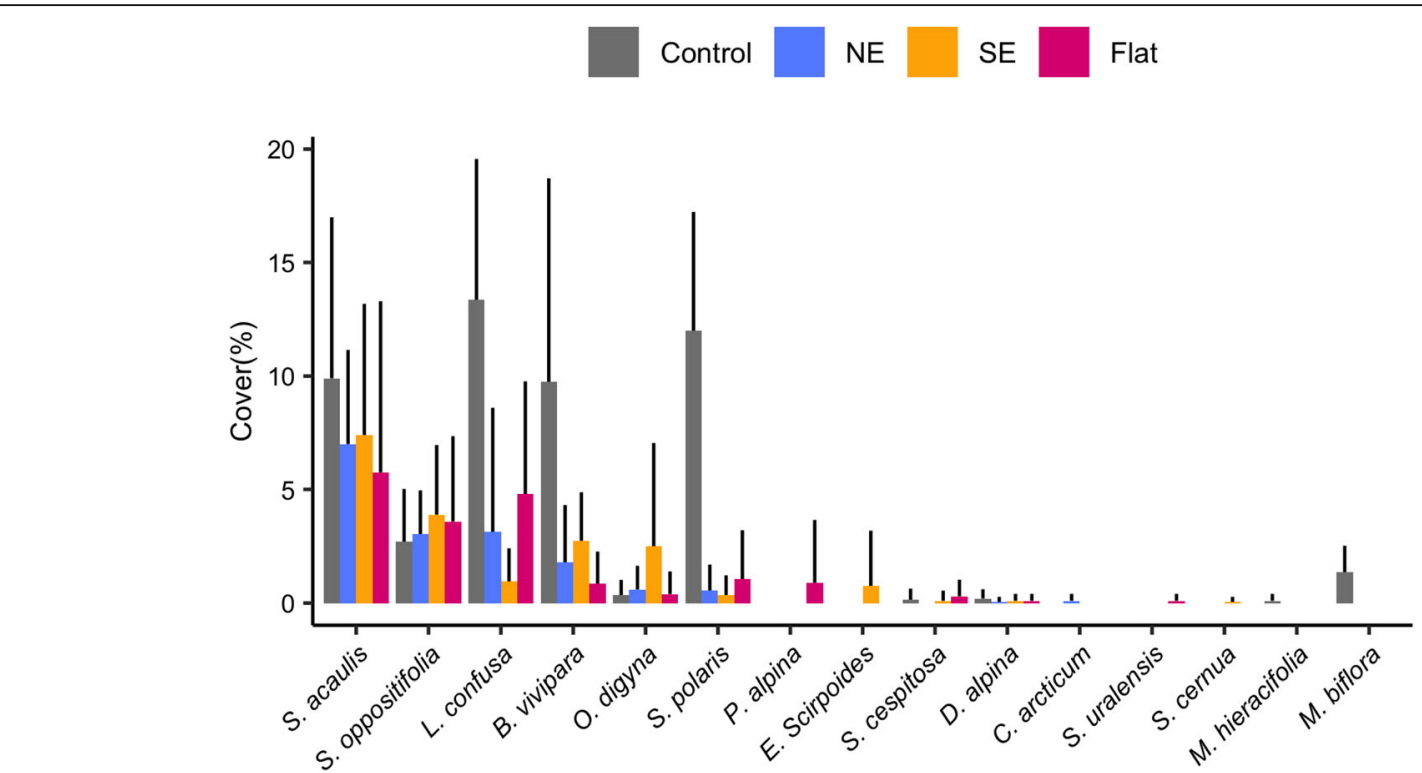

Fig. 3 The cover (\%) of the species found on the open plots arranged in descending order of the mean of means of coal pile sites. The error bar stands for standard deviation

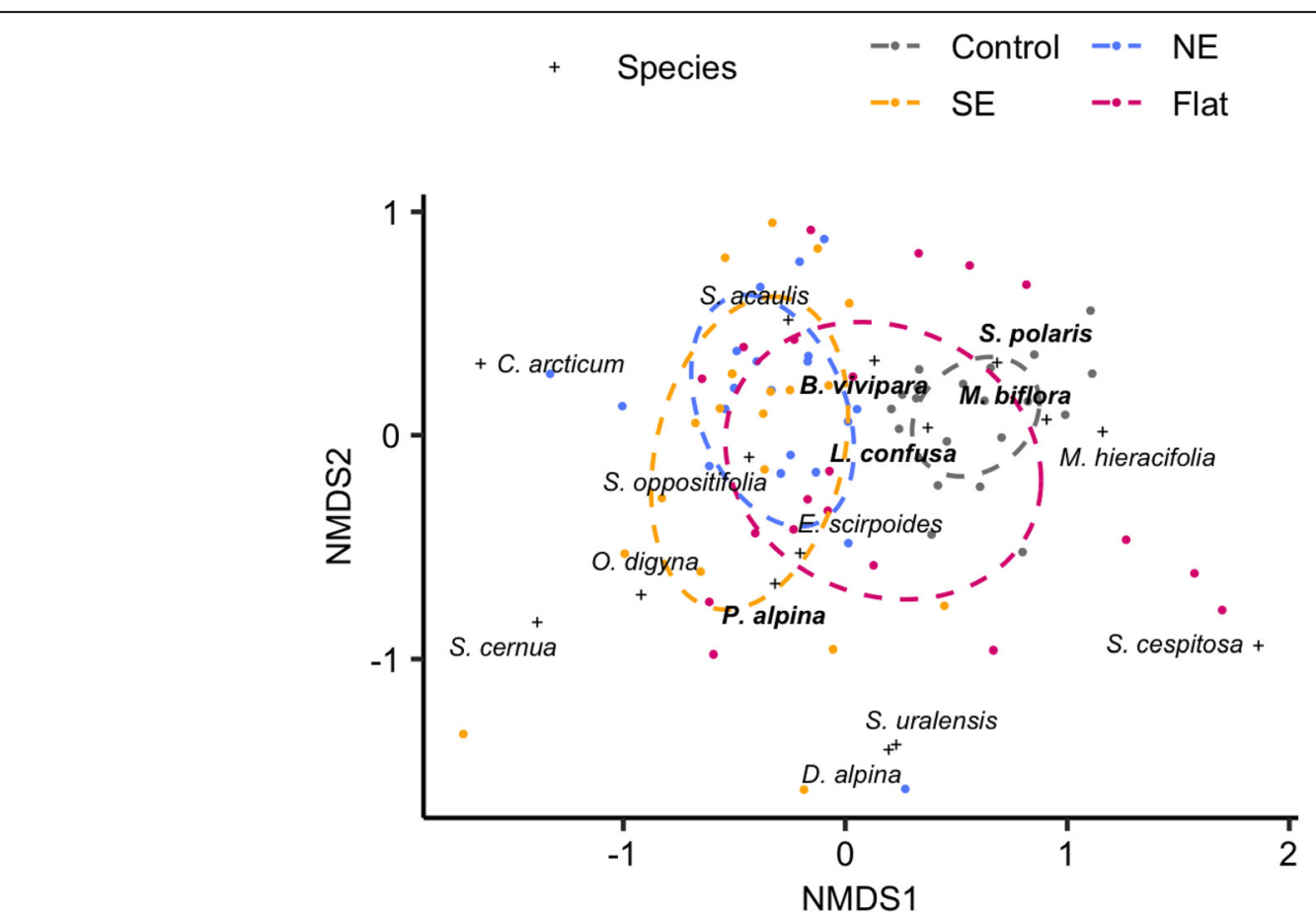

Fig. 4 NMDS ordination plot of plant communities in the control site (control), flat ground (Flat), the north-east facing slope (NE), and the southeast facing slope (SE). The color dots indicate surveyed plots per site, and the black plus sign (+) indicates the species found. The ellipses for sites were drawn based on the standard deviation of point scores. The bold text species are indicator species; S. polaris and M. biflora are indicator species for the control site. L. confusa is an indicator species for the control, flat ground, and the NE. B. vivipara is an indicator species for the control, NE, and the SE. P. alpine is an indicator species for the flat ground. The stress value of NMDS was 0.21 
ground plant community was significantly different from the SE. NMDS ordination plot (stress value $=0.21$ ) and the result of PERMANOVA supported this division (Bonferroni correction; Pseudo- $F=9.88, \mathrm{df}=3, P<$ 0.001 for all sites; Pseudo- $F=12.33$, df $=1, P<0.001$ for the control vs. the flat ground; Pseudo- $F=25.01$, df $=1, P<0.001$ for the control vs. the NE; Pseudo- $F=$ 22.89, $\mathrm{df}=1, P<0.001$ for the control vs. the SE; Pseudo- $F=3.19, \mathrm{df}=1, P=0.060$ for the flat ground vs. the NE; Pseudo- $F=4.70, \mathrm{df}=1, P=0.003$ for the flat ground vs. the SE; Pseudo- $F=1.85, \mathrm{df}=1, P=0.559$ for the NE vs. the SE). As for indicator species of these communities, both S. polaris and M. biflora were significantly associated with the control site (IndVal $=0.927, P$ $<0.005$ for S. polaris; IndVal $=0.866, P=0.005$ for $M$. biflora). P. alpina was an indicator of the flat ground (IndVal $=0.387, P=0.035$ ). $L$. confusa was an indicator species for the combination of the control, flat ground, and the NE (IndVal $=0.875, P=0.050)$. B. vivipara was an indicator species for the combination of the control, $\mathrm{NE}$, and the SE (IndVal $=0.851, P<0.005)$.

\section{Interaction effects of $S$. acaulis on associated plants}

We showed that the interaction effects of $S$. acaulis were facilitation to competition according to the site and the cushion diameter (Fig. 5). Rarefaction curves of cushions and open plots on the NE (Fig. 5a), control (Fig. 5c), and the flat ground (Fig. 5d) slightly deviated as the cumulative area increased, but in the SE (Fig. 5b), the curves were largely overlapped. This result is well depicted in RII per site (Fig. 5e). Even though 95\% CIs of all RIIs included 0 , RIIs showed a decreasing trend in the order of the NE, SE, control, and the flat ground. The median log diameter of cushions also followed this order.

The cushion size was significantly larger in the flat ground than in the NE (Tukey's HSD, $t=-2.83, P=$ 0.026 for the flat ground vs. the NE). However, it was not significantly different between other sites (Tukey's HSD; $t=1.77, P=0.29$ for the control vs. the flat ground; $t=-1.06, P=0.71$ for the control vs. the $\mathrm{NE} ; t=-0.44, P=0.97$ for the control vs. SE; $t=-$ 2.21, $P=0.12$ for the flat ground vs. the SE; $t=0.62$, $P=0.93$ for the NE vs. SE).

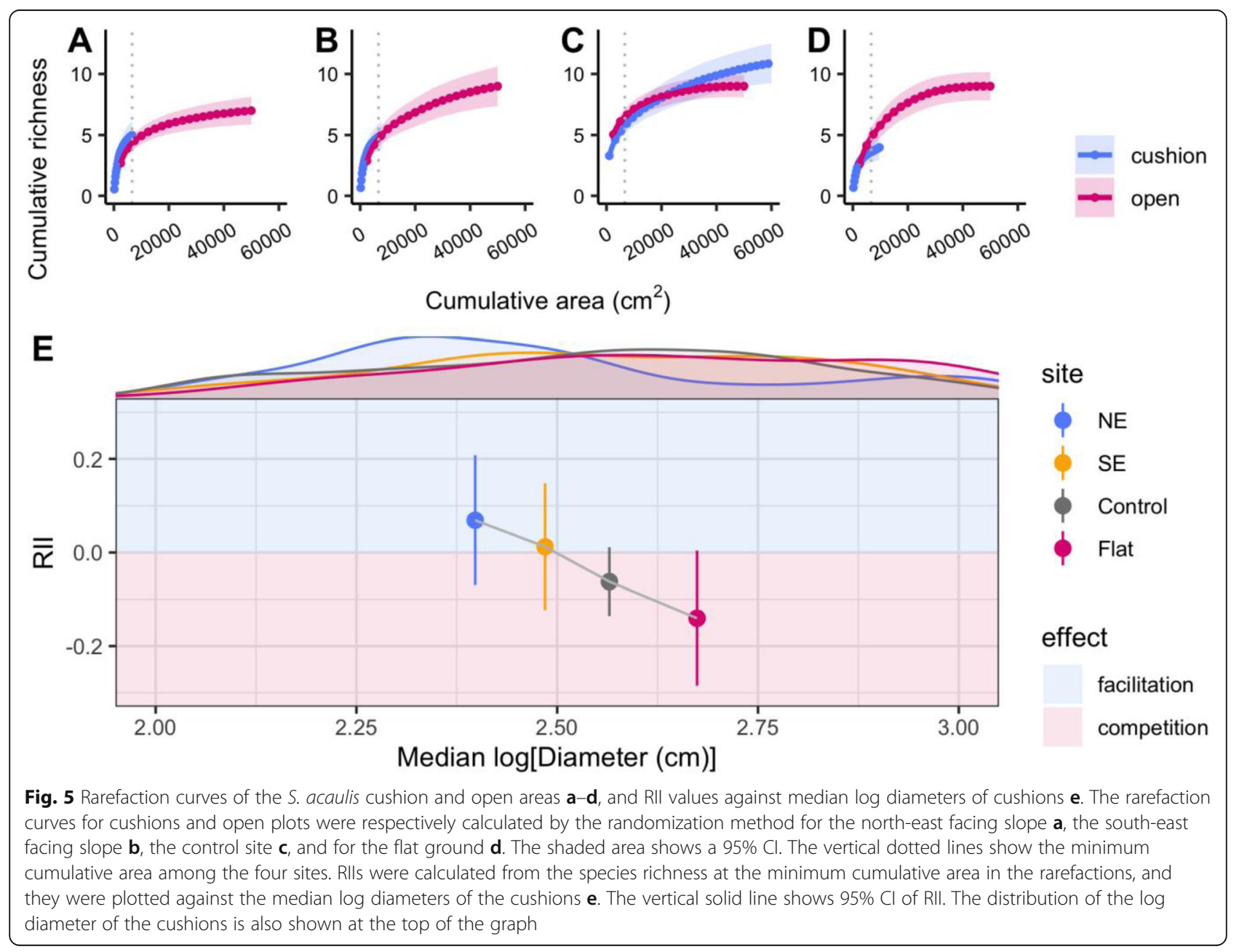




\section{Discussion}

On the coal piles, soils were not formed yet, and the overall vegetation cover was sparse compared to the control site. Our results showed that $S$. acaulis was the most dominant plant on the coal piles on any slope. Also, S. oppositifolia and O. digyna, the well-known pioneer species in a glacier foreland, are observed with relatively high coverage together (Erschbamer and Retter 2004; Erschbamer and Mayer 2011). Not only S. oppositifolia or O. digyna, but also $S$. acaulis is known as a pioneer species in a glacier foreland (Kjær et al. 2018). In this respect, we concluded that the coal piles could be regarded as in the early stage of succession based on the scarcity of soils and the high coverage of pioneer species. Therefore, S. acaulis could be a dominant pioneer plant in an abandoned coal pile as well as in a glacier foreland.

Many cushion plants are also reported as pioneer species, such as S. oppositifolia (Erschbamer and Mayer 2011), Thylacospermum caespitosum (Dvorský et al. 2013), Azorella selago (Aubert et al. 2014), Philonotis esquelensis, Bryum pseudotriquetrum, and Pohlia wahlenbergii (Gavini et al. 2019). Their low dome-shaped growth form often beneficial to colonize harsh and barren environments (Aubert et al. 2014). This feature seemed to be a key factor to be a pioneer species in the alpine or High Arctic tundra.

Also, S. acaulis appeared to tolerate the coal-related stress well because it was still the dominant species on the coal piles despite a $32 \%$ reduction in plant cover compared to the control site. No data has been reported for the physical or chemical effect of coal piles on $S$. acaulis, but its high coverage was also observed on a coal pile in previous literature (Kojima 2004). Its dominance and comparable cushion size to the control site supported the hypothesis that $S$. acaulis is tolerant of the negative effect of the coal piles.

On the other hand, we found that some species poorly tolerated the coal piles. For example, the cover of $L$. confusa, B. vivipara, S. polaris, and M. biflora were dramatically decreased on the coal piles. Specifically, S. polaris and $M$. biflora were strongly negatively associated with the coal piles. This result can be due to the toxicity of AMD on the coal piles, limited soil moisture, or scarce nutrient. However, S. polaris showed the highest cover in an abandoned coal mine near $\mathrm{Ny}$ - $\mathrm{Alesund}$ in a previous report (Kojima 2004). Therefore, we cannot generalize our result to the vast area of the Arctic tundra without considering microclimate, local soil characteristics, or other abiotic factors which might be crucial to determine the habitat suitability of species.

Moreover, we found that the interaction effect of $S$. acaulis was slightly changed by coal piles even though there was no statistically significant difference. In the first place, the interaction effect in the control site was the competition at the small cumulative area. However, as the cumulative area increased further, the interaction effect turned to facilitation. Compared to the control site, the flat ground on the coal pile showed more negative RII. However, we did not measure any abiotic factors in this research. Therefore, further research is needed to determine what factors of coal piles affects the interaction effect of $S$. acaulis.

The interaction of $S$. acaulis in the three coal pile sites changed from positive to negative when the slope aspect was turned to a lesser stressful condition. Plants living on the NE faced the harshest condition because its slope aspect limited incident light. The SE also had stressed conditions, but it is more suitable to live there than on the NE. Compared to the two slopes, the flat ground is in the least stressed condition because the slope steepness is often related to the physical damages, such as surface material movement and water runoff (Nagamatsu et al. 2002; Wang et al. 2014). Soil erosion generated by runoff also causes soil water loss, and it affects seedling emergence, mortality, and seed production (Espigares et al. 2011). Therefore, the slope area is much heavily affected than on the flat ground. In a stressed environment, the growth rate of $S$. acaulis is usually lower, which results in a smaller cushion diameter distribution. This fact is in good agreement with the actual observed cushion size distribution in our result.

The change in the interaction effect along the stress gradient is a consistent result with the stress gradient hypothesis (SGH) (Bertness and Callaway 1994). According to the SGH, facilitative effects tend to increase along stress gradients. Previous studies on the SGH mainly focused on the altitudinal stress gradient (Antonsson et al. 2009; Schöb et al. 2013; Bonanomi et al. 2016). However, only a few studies reported the changes in the interaction strength of plants, according to slope aspects (Badano et al. 2005; Farji-Brener et al. 2009). Our results support that SGH can explain plant interaction changes with stress gradients along the slope direction.

On the other hand, it could be argued that the decrease in RII was not due to the decrease in stress gradient but due to an increase in cushion size because the RII showed a decreasing trend as the cushion size increased. However, the diameters of cushions among the three sites showed only small differences. Also, only the cushion size between the NE and the flat ground showed a significant difference. In a current study about the relationship between cushion sizes and facilitation, another cushion plant Arenaria polytrichoides showed a higher facilitation effect in a larger cushion (Yang et al. 2017). Therefore, it is more convincing that the RII was affected by the slope direction, which determined abiotic stress. From this point of view, a cushion size seemed 
not a cause, but the result of different growth rates of $S$. acaulis in different abiotic stress conditions.

One limitation of our research is a small sample size on coal piles because of sparse vegetation. More accurate interactions can be assessed when the two rarefaction curves level off. Even the control site where 300 cushions were sampled did not level off yet. However, the gap between the cushion rarefaction curve and the open plot rarefaction curve increased as the cumulative area increased. Consequently, RII can be significantly different from 0 when enough number of cushions is sampled.

\section{Conclusions}

This research showed that (1) $S$. acaulis was a pioneer plant in the early stage of succession on abandoned coal piles, and (2) a shift in interaction effects of S. acaulis according to the slope and its direction. According to the results, $S$. acaulis was a dominant species on coal piles regardless of slope aspects. A facilitation effect of $S$. acaulis appeared on the north-east facing slope, which was the shaded slope, but it was shifted to a neutral effect on the south-east facing slope or competition on the flat ground. Although all of them were not statistically significant, it was a consistent result with SGH. To sum up, $S$. acaulis increases vegetation cover on coal piles and also ameliorates stress on a shaded slope, which may gradually cause the deposition of soils above the coals. Therefore, it plays a vital role in the early stage of succession on coal piles in Svalbard.

\section{Abbreviations}

SGH: Stress gradient hypothesis; NE: North-east facing slope; SE: South-east facing slope; RIl: Relative interaction intensity; ANOVA: Analysis of variance; HSD: Honestly significant difference; NMDS: Non-metric multidimensional scaling; PERMANOVA: Permutational multivariate analysis of variance; IndVal: Indicator value index; Cl: Confidence interval

\section{Acknowledgements}

This research was supported by a National Research Foundation of Korea Grant from the Korean Government (NRF-2011-0021071). Also, it was partially supported by Hyundai Motor Chung Mong-Koo Foundation. We are grateful for fieldwork support and comments from Deokjoo Son and Saeromi Mun.

\section{Authors' contributions}

$\mathrm{MO}$ performed the analysis and wrote the manuscript. EJ conceived the study, carried out the field study, and reviewed/edited the manuscript. All authors read and approved the final manuscript.

\section{Funding}

This research was supported by a National Research Foundation of Korea Grant from the Korean Government (NRF-2011-0021071). Also, it was partially supported by Hyundai Motor Chung Mong-Koo Foundation.

\section{Availability of data and materials}

The datasets generated during and/or analyzed during the current study are available from the corresponding author on reasonable request.

Ethics approval and consent to participate Not applicable.
Consent for publication

Not applicable.

\section{Competing interests}

The authors declare that they have no competing interests.

Received: 6 November 2020 Accepted: 8 December 2020 Published online: 04 January 2021

\section{References}

Alday JG, Marrs RH, Martínez-Ruiz C. Soil and vegetation development during early succession on restored coal wastes: a six-year permanent plot study. Plant Soil. 2012;353:305-20.

Anderson MJ. A new method for non-parametric multivariate analysis of variance Austral Ecol. 2001;26:32-46.

Anthelme F, Buendia B, Mazoyer C, Dangles O. Unexpected mechanisms sustain the stress gradient hypothesis in a tropical alpine environment. J Veg Sci. 2012;23:62-72.

Antonsson H, Björk RG, Molau U. Nurse plant effect of the cushion plant Silene acaulis (L.) Jacq. in an alpine environment in the subarctic Scandes, Sweden Nurse plant effect of Silene acaulis in alpine tundra. Plant Ecol Divers. 2009;2: $17-25$.

Armas C, Ordiales R, Pugnaire Fl. Measuring plant interactions: a new comparative index. Ecology. 2004;85(10):2682-6.

Aubert S, Boucher F, Lavergne S, Renaud J, Choler P. 1914-2014: A revised worldwide catalogue of cushion plants 100 years after Hauri and Schröter. Alp Botany. 2014;124:59-70.

Badano El, Cavieres LA, Molina-Montenegro MA, Quiroz CL. Slope aspect influences plant association patterns in the Mediterranean matorral of central Chile. J Arid Environ. 2005;62(1):93-108.

Baig MN. Natural revegetation of coal mine spoils in the rocky mountains of Alberta and its significance for species selection in land restoration. Mt Res Dev. 1992;12(3):285-300.

Bertness MD, Callaway R. Positive interactions in communities. Trends Ecol Evol. 1994;9:187-91.

Bonanomi G, Stinca A, Chirico GB, Ciaschetti G, Saracino A, Incerti G. Cushion plant morphology controls biogenic capability and facilitation effects of Silene acaulis along an elevation gradient. Funct Ecol. 2016;30:1216-26.

Carter CT, Ungar IA. Aboveground Vegetation. Seed Bank and Soil Analysis of a 31-year-old Forest Restoration on Coal Mine Spoil in Southeastern Ohio. Am Midl Nat. 2002;147(1):44-59.

Cavieres LA, Brooker RW, Butterfield BJ, Cook BJ, Kikvidze Z, Lortie CJ, et al. Facilitative plant interactions and climate simultaneously drive alpine plant diversity. Ecol Lett. 2014;17:193-202.

Colwell RK, Coddington JA. Estimating Terrestrial Biodiversity through Extrapolation. Philos Trans R Soc Lond B Biol Sci. 1994:345:101-18.

De Cáceres M, Legendre P. Associations between species and groups of sites: indices and statistical inference. Ecology. 2009;90(12):3566-74.

De Cáceres M, Legendre P, Moretti M. Improving indicator species analysis by combining groups of sites. Oikos. 2010;119(10):1674-84.

Dowarah J, Deka Boruah HP, Gogoi J, Pathak N, Saikia N, Handique AK. Ecorestoration of a high-sulphur coal mine overburden dumping site in northeast India: A case study. J Earth Syst Sci. 2009;118:597-608.

Dufrêne $M$, Legendre P. Species assemblages and indicator species: the need for a flexible asymmetrical approach. Ecol Monogr. 1997;67(3):345-66.

Dvorský M, Doležal J, Kopecký M, Chlumská Z, Janatková K, Altman J, et al. Testing the stress-gradient hypothesis at the roof of the world: effects of the cushion plant Thylacospermum caespitosum on species assemblages. PLoS One. 2013;8(1):e53514.

Elberling B, Søndergaard J, Jensen LA, Schmidt LB, Hansen BU, et al. Arctic vegetation damage by winter-generated coal mining pollution released upon thawing. Environ Sci Technol. 2007:41(7):2407-13.

Erschbamer B, Mayer R. Can successional species groups be discriminated based on their life history traits? A study from a glacier foreland in the Central Alps. Plant Ecol Divers. 2011:4:341-51.

Erschbamer B, Retter V. How long can glacier foreland species live? Flora. 2004; 199:500-4.

Espigares T, Moreno-de las Heras M, Nicolau JM. Performance of vegetation in reclaimed slopes affected by soil erosion. Restor Ecol. 2011;19(1):35-44. 
Farji-Brener AG, Chinchilla FA, Magrach A, Romero V, Ríos M, Velilla M, et al. Slope orientation enhances the nurse effect of a paramo shrub. Hypericum irazuense (Hypericaceae) in Costa Rica. J Trop Ecol. 2009;25:331-5.

Fields-Johnson CW, Zipper CE, Burger JA, Evans DM. Forest restoration on steep slopes after coal surface mining in Appalachian USA: Soil grading and seeding effects. For Ecol Manag. 2012;270:126-34.

Forsythe GE, Malcom MA, Moler CB. Computer methods for mathematical computations. Englewood Cliffs: Prentice-Hall; 1977.

Frenot Y, Gloaguen JC, Cannavacciuolo M, Bellido A. Primary succession on glacier forelands in the subantarctic Kerguelen Islands. J Veg Sci. 1998;9(1): 75-84.

Gavini SS, Suárez GM, Ezcurra C, Aizen MA. Facilitation of vascular plants by cushion mosses in high-Andean communities. Alp Bot. 2019;129(2):137-48.

Gotelli NJ, Colwell RK. Quantifying biodiversity: procedures and pitfalls in the measurement and comparison of species richness. Ecol Lett. 2001;4:379-91.

Hermansen P. Svalbard /Spitzbergen Guide. Oslo: Myrland Media; 2007.

Hollesen J, Elberling B, Hansen BU. Modelling subsurface temperatures in a heat producing coal waste rock pile, Svalbard ( $\left.78^{\circ} \mathrm{N}\right)$. Cold Reg Sci Technol. 2009; 58(1-2):68-76.

Kjær U, Olsen SL, Klanderud K. Shift from facilitative to neutral interactions by the cushion plant Silene acaulis along a primary succession gradient. J Veg Sci. 2018:29:42-51.

Kojima S. Three-year vegetation change in the Arctic environment as observed in a permanent plot in Ny-Ålesund, Svalbard. Polar Biosci. 2004;17:123-7.

Lee YK, Jung JY, Hwang Y, Lee K, Han DD, Lee EJ. Beautiful Arctic Tundra Plants. Seoul: GeoBook Publishing Co.: 2014

Liu M, Wang Y, Sun J, Zhang Z, Xu X, Zhou H, et al. Shift in nurse effect from facilitation to competition with increasing size of Salix cupularis canopy in a desertified alpine meadow on the Tibetan Plateau. Catena. 2020;195:104757.

Molenda O, Reid A, Lortie CJ. The Alpine cushion plant Silene acaulis as foundation species: a bug' s-eye view to facilitation and microclimate. PLoS One. 2012;7(5):e37223.

Moreno-de las Heras M, Nicolau JM, Espigares T, Moreno-de las Heras M, Nicolau $J$ M. 2011, Performance of vegetation in reclaimed slopes affected by soil erosion: Restoration Ecology, v. 19, no. 1, p. 35-44. T. Vegetation succession in reclaimed coal-mining slopes in a Mediterranean-dry environment. Ecol Eng. 2008:34:168-78.

Nagamatsu D, Seiwa K, Sakai A. Seedling establishment of deciduous trees in various topographic positions. J Veg Sci. 2002;13(1):35-44.

Oksanen J, Blanchet FG, Kindt R, Legendre P, Minchin PR, O'Hara RB, et al. vegan: Community Ecology Package. 2019. R package version 2.5-6. https://CRAN.Rproject.org/package=vegan.

R Core Team. R: A Language and Environment for Statistical Computing. Vienna: R Foundation for Statistical Computing; 2020.

Ren $\mathrm{H}$, Yang L, Liu N. Nurse plant theory and its application in ecological restoration in lower subtropics of China. Prog Nat Sci. 2008;18:137-42.

Rønning, Ol, flora of Svalbard, Norsk polarinstitutt; 1996.

Rubel F, Kottek M. Observed and projected climate shifts 1901-2100 depicted by world maps of the Köppen-Geiger climate classification. Meteorol Zeitschrift. 2010;19(2):135-41.

Schöb C, Armas C, Guler M, Prieto I, Pugnaire FI. Variability in functional traits mediates plant interactions along stress gradients. J Ecol. 2013;101:753-62.

Schöb C, Butterfield BJ, Pugnaire Fl. Foundation species influence trait-based community assembly. New Phytol. 2012;196(3):824-34.

Singh AN, Singh JS. Experiments on Ecological Restoration of Coal Mine Spoil using Native Trees in a Dry Tropical Environment, India: A Synthesis. New For. 2006:31:25-39.

Søndergaard J, Elberling B, Asmund G, Gudum C, Iversen KM. Temporal trends of dissolved weathering products released from a high Arctic coal mine waste rock pile in Svalbard (78N). Appl Geochemistry. 2007;22:1025-38.

Stange R. Spitsbergen - Svalbard. Myrland: Oslo; 2007.

Wang N, Jiao JY, Lei D, Chen Y, Wang DL. Effect of rainfall erosion: seedling damage and establishment problems. Land Degrad Dev. 2014;25(6):565-72.

Yang Y, Chen JG, Schöb C, Sun H. Size-mediated interaction between a cushion species and other non-cushion species at high elevations of the Hengduan Mountains, SW China. Front Plant Sci. 2017;8:465.

\section{Publisher's Note}

Springer Nature remains neutral with regard to jurisdictional claims in published maps and institutional affiliations.

Ready to submit your research? Choose BMC and benefit from:

- fast, convenient online submission

- thorough peer review by experienced researchers in your field

- rapid publication on acceptance

- support for research data, including large and complex data types

- gold Open Access which fosters wider collaboration and increased citations

- maximum visibility for your research: over $100 \mathrm{M}$ website views per year

At $\mathrm{BMC}$, research is always in progress.

Learn more biomedcentral.com/submissions 